\title{
ANALISIS PENGARUH CITRA MEREK, HARGA DAN KUALITAS PRODUK TERHADAP KEPUTUSAN PEMBELIAN HANDPHONE SAMSUNG (BERBASIS ANDROID ) TAHUN 2019
}

(Studi kasus pada dosen dan mahasiswa pengguna smartphone Samsung Di Universitas Boyolali)

\author{
Joko Sakurat $^{1}$, Listyowati $^{2}$, Unna Ria Safitri ${ }^{3}$ \\ jokosakurat1@gmail.com \\ Universitas Boyolali
}

\begin{abstract}
ABTRACT
This research aims to know the influence of brand image, price, and product quality of samsung smartphone purchases on all student users of samsung mobile phones (android-based) at the University of Boyolali. The technique of collecting data which used of these tests are the questionnaire and the interviews conducted in the months april and stay there until $2019 \mathrm{mt}$ gas bali on june. The technique of the sample collection that is used accidental the sampling method of, all of the data have been analyzed from the analysis the percentage of, it is anticipated that analysis linear regression of multiple, the fit and proper test classical economic assumptions agreed to at, the test and been approved $f$, a satire or a reflecti efforts whatever survives this test and coefficients of determination. Percent of the population in this research was lecturers and students the user of mobile phone samsung ( the android based) at the university of boyolali , with samples from 100 respondents in the present study. From hypothesis testing in mind that the goal of brand, price and quality of products simultaneously influential buying decision significantly to Samsung mobile phone (android-based). Partially variable of influential brand image quality significantly to purchase Samsung mobile (android-based). While variable pricing and product quality partially do not affect purchase decisions significantly to Samsung mobile phone (android-based).
\end{abstract}

Keywords: brand image, price, product quality, purchase decision.

\section{PENDAHULUAN \\ 1.1 Latar belakang}

Perkembangan dunia modern dan globalisasi saat ini suatu kebutuhan akan komunikasi adalah hal yang sangat penting bagi setiap kalangan masyarakat.Kebutuhan tersebut berdampak pada meningkatnya permintaan akan berbagai jenis alat komunikasi yang mengakibatkan semakin banyaknya persaingan dalam dunia bisnis dibidang telekomunikasi. Produsen-produsen alat komunikasi yang terus bermunculan menyebabkan terjadinya persaingan yang kompetitif antar produsen, dalam hal menciptakan produk maupun mempertahankan konsumen yang loyal. Membanjirnya produk handphone di pasaran mempengaruhi sikap seseorang terhadap pembelian dan pemakaian handphone.

Pembelian suatu handphone bukan lagi untuk memenuhi keinginan, melainkan karena kebutuhan. Ditambah dengan ditemukannya konsumen yang memutuskan memilih menggunakan produk tertentu (handphone) dalam rangka memperjelas identitas diri, agar dipandang baik dalam komunitas tertentu. Konsep produk menyatakan bahwa konsumen akan lebih menyukai produk - produk yang menawarkan kualitas paling bermutu, berprestasi dan inovatif. Saat ini banyak perusahaan yang berlomba-lomba memproduksi handphone yang berkualitas dan menarik dengan harga yang sangat bersaing, dari harga yang murah hingga harga yang relative mahal. Samsung merupakan salah satu jenis handphon 
atau smartphone yang saat ini banyak digunakan oleh masyarakat Indonesia khususnya di kota Boyolali. Samsung sendiri akhir- akhir ini tengah menciptakan handphone yang berbasis android dengan kualitas yang lebih canggih, yang pada saat ini bersaing ketat dengan produkproduk handphone lainnya Salah satu produk Samsung yang sedang menjadi pusat perhatian khalayak luas yaitu produk handphone Samsung berbasis android dengan prosesor Exynos. Berdasarkan uraian diatas dapat diketahui tentang pengaruh citra merek, harga dan kualitas produk terhadap keputusan pembelian handphone Samsung di kalangan Universitas Boyolali maka penelitian ini diberi judul "Analisis Pengaruh Citra Merek, Harga dan Kualitas Produk Terhadap Keputusan Pembelian Handphone Samsung (Berbasis Android) Tahun 2019".

\subsection{PERUMUSAN MASALAH}

Berdasarkan latar belakang diatas, maka dapat dirumuskan permasalahan sebagai berikut:

1. Apakah citra merek, harga dan kualitas produk secara simultan berpengaruhi terhadap keputusan pembelian handphone SAMSUNG (berbasis android)?

2. Apakah citra merek,harga dan kualitas produk secara parsial berpengaruhi terhadap keputusan pembelian handphone

SAMSUNG(berbasis android).

\section{KAJIAN LITERATUR DAN PENGEMBANGAN HIPOTESIS}

\subsection{LANDASAN TEORI \\ Pemasaran}

Pemasaran merupakan salah satu dari kegiatan-kegiatan pokok yang dilakukan oleh perusahaan untuk mempertahankan kelangsungan hidupnya, untuk berkembang, dan mendapatkan laba
(Dharmmerta dan Handoko, 2000: 3). Pemasaran dapat juga dikatakan sebagai suatu proses sosial yang didalamnya terdapat individu dan kelompok apa yang mereka butuhkan dan inginkan dengan menciptakan, menawarkan dan secara bebas mepertukarkan produk yang bernilai dengan pihak lain.

Citra Merek

Merek merupakan hal yang sangat penting baik bagi konsuen maupun bagi produsen. Merek juga membantu meyakinkan konsumen, bahwa mereka akan mendapatkan kualitas yang konsisten setiap kali memilih merek tersebut saat melakukan pembelian. Bila tidak ada merek konsumen harus mengevaluasi semua produk setiap kali akan melakukan pembelian. Namun, saat konsumen telah memiliki kepercayaan terhadap sebuah merek akan memudahkan pada saat akan melakukan pembelian, (Sulistyari, 2012).

\section{Harga}

Saladin (2007) menyatakan bahwa harga adalah jumlah moneter yang dibebankan oleh suatu unit usaha kepada pembeli atau pelanggan atas barang atau jasa yang dijual atau diserahkan. Sedangkan Menurut Alma (2007), pada prinsipnya harga jual harus dapat menutupi biaya penuh ditambah dengan laba yang wajar. Tjiptono (2008) menyatakan bahwa harga adalah sejumlah uang dan jasa atau barangbarang yang tersedia ditukarkan oleh pembeli untuk mendapatkan berbagai pilihan produk-produk dan jasa-jasa yang disediakan penjual.

\section{Kualitas produk}

Perusahaan dalam menjalankan suatu bisnis, produk maupun jasa yang dijual harus memiliki kualitas yang baik atau sesuai dengan harga yang ditawarkan agar suatu usaha atau perusahaan dapat bertahan dalam menghadapi persaingan, terutama persaingan dari segi kualitas. Menurut Kotler dan Keller (2012:49) mengemukakan bahwa kualitas adalah keseluruhan ciri serta sifat dari suatu produk atau pelayanan yang berpengaruh pada kemampuannya untuk memuaskan kebutuhan yang dinyatakan atau tersirat.

Sedangkan menurut Davis (dalam Lupiyoadi, 2008),kualitas produk adalah suatu kondisi dinamis yang berhubungan dengan barang ,jasa ,manusia, produk,dan lingkungan yang memenuhi atau melebihi 
harapan..

\section{Keputusan Pembelian}

Menurut Kotler dan Keller (2012 : 166), proses keputusan pembelian terdiri dari lima tahap yang dilakukan oleh seorang konsumen sebelum sampai pada keputusan pembelian dan selanjutnya pasca pembelian. Keputusan pembelian yang dilakukan oleh konsumen dapat terjadi apabila kosumen sudah mendapatkan pelayanan dari pemberian jasa dan setelah itu konsumen merasakan adanya kepuasan dan ketidakpuasan, maka dari itu konsepkonsep keputusan pembelian tidak lepas dari konsep kepuasan pelanggan. Secara umum manusia bertindak rasional dan mempertimbangkan segala jenis informasi yang tersedia dan mempertimbangkan segala sesuatu yang mungkin bisa muncul dari tindakannya sebelum melakukan sebuah perilaku tertentu.

\subsection{PENGEMBANGAN HIPOTESIS}

Atas dasar kerangka pemikiran teoritik dan model penelitian tersebut, maka hipotesis penelitian ini adalah sebagi berikut:

$\mathrm{H}_{1}$ : Citra merek, harga, dan kualitas produk secara simultan berpengaruh signifikan terhadap keputusan pembelian handphone Samsung (berbasis android) di Universitas Boyolali.

$\mathrm{H}_{2}$ : Citra merek, harga, dan kualitas produk secara parsial berpengaruh signifikan terhadap keputusan pembelian handphone Samsung (berbasis android) di Universitas Boyolali.

\section{METODE PENELITIAN}

Berdasarkan jenis data yang digunakan, penelitian ini merupakan penelitian kuantitatif, sedangkan berdasarkan bentuk penelitiannya, penelitian ini merupakan asosiasi karena menganalisa pengaruh variabel independen terhadap variabel dependen. Metode pengumpulan data yang digunakan dalam penelitian adalah dengan menyebar koesioner kepada responden yaitu beberapa mahasiswa dan dosen pengguna handphone samsung di universitas Boyolali. Data yang digunakan dalam penelitian ini adalah data primer hasil jawaban kuesioner. Teknik analisa yang digunakan dalam penelitian ini adalah uji asumsi klasik, uji regresi linier berganda, uji $F$, uji t dan uji koefisien determinasi.

\section{HASIL DAN PEMBAHASAN}

Hasil analisis data menghasilkan nilainilai yang digunakan untuk membuktikan hipotesis dari penelitian, yaitu sebagai berikut:

a. Hipotesis Pertama

Uji F digunakan apakah citra merek, harga, dan kualitas produk secara simultan berpengaruh terhadap keputusan pembelian.

Hasil Uji F 
Berdasarkan tabel diatas maka dapat dijelaskan sebagai berikut :

Jika $F_{\text {hitung }}>F_{\text {tabel }}$ dan nilai signifikan < 0,05, maka $\mathrm{H}_{0}$ ditolak dan $\mathrm{H}_{\mathrm{a}}$ diterima. Hal ini menujukan bahwa citra merek, harga, dan kualitas produk berpengaruh signifikan terhadap keputusan pembelian.

Jika $F_{\text {hitung }}<\mathrm{F}_{\text {tabel }}$ dan nilai signifikan $>0,05$, maka $\mathrm{H}_{0}$ diterima dan $\mathrm{H}_{\mathrm{a}}$ ditolak. Hal ini menujukan bahwa citra merek, harga, dan kualitas produk tidak berpengaruh signifikan terhadap keputusan pembelian. Berdasarkan hasil analisis regresi berganda dengan uji secara simultan bahwa $F_{\text {hitung }}$ sebesar $26,640>\mathrm{F}_{\text {tabel }}$ sebesar 2.70 dan nilai signifikasi $0,000<0,05$. Hal ini menunjukan bahwa citra merek, harga, dan kualitas produk berpengaruh signifikan terhadap keputusan pembelian. Sama seperti penelitian terdahulu yang dilakukan Johan Samuel Siregar, Erni Widiastuti (2017) hasil penelitiannya menjelaskan bahwa citra merek, harga, dan kualitas produk secara simultan berpengaruh signifikan terhadap keputusan pembelian. Untuk itu dalam upaya meningkatkan volume penjualan produk diharapkan perusahan selalu menjaga kualitas baik produknya, menjual produk dengan harga yang kompetitif dan memberi pelayanan penjualan yang sebaikbaiknya. Agar konsumen lebih percaya pada produk-produk perusahaan tersebut. Sedangkan nilai koefisien determinasi $\left(\mathrm{R}^{2}\right)$ sebesar 0,454 memiliki pengertian bahwa citra merek, harga, dan kualitas secara bersamasama mampu mempengaruhi variabel keputusan pembelian sebesar 45,4\% selebihnya $54,6 \%$ dipengaruhi oleh variabel lain yang tidak dimasukkan dalam penelitian ini.

b. Hipotesis kedua

Uji t digunakan apakah citra merek, harga, dan kualitas produk secara parsial berpengaruh terhadap keputusan pembelian.
ANOVA ${ }^{\mathrm{a}}$

\begin{tabular}{|c|l|l|l|l|l|}
\hline Model & $\begin{array}{l}\text { Sum of } \\
\text { Squares }\end{array}$ & Df & $\begin{array}{l}\text { Mean } \\
\text { Square }\end{array}$ & F & $\begin{array}{l}\text { Sig } \\
.\end{array}$ \\
\hline $\begin{array}{c}\text { Regre } \\
\text { ssion }\end{array}$ & 501.449 & 3 & 167.150 & $\begin{array}{l}26 . \\
640\end{array}$ & $\begin{array}{l}.00 \\
0^{\mathrm{b}}\end{array}$ \\
\hline $\begin{array}{c}\text { Resid } \\
\text { ual }\end{array}$ & 602.341 & 96 & 6.274 & & \\
Total & 1103.790 & 99 & & & \\
\hline
\end{tabular}

Hasil Uji t

\begin{tabular}{|l|l|l|l|l|l|}
\hline & \multicolumn{2}{|l|}{$\begin{array}{l}\text { Unstandardized } \\
\text { Coefficients }\end{array}$} & $\begin{array}{l}\text { Standardized } \\
\text { Coefficients }\end{array}$ & & \\
\cline { 2 - 5 } Model & B & $\begin{array}{l}\text { Std. } \\
\text { Error }\end{array}$ & Beta & $T$ & Sig. \\
CITRA & .4 .307 & 2.610 & & 1.267 & .208 \\
MEREK & .422 & .152 & .372 & 2.776 & .007 \\
\hline HARGA & .223 & .120 & .197 & 1.853 & .067 \\
KUALITAS & .177 & .145 & .173 & 1.219 & .226 \\
\hline
\end{tabular}

Berdasarkan tabel diatas maka dapat dijelaskan sebagai berikut :

1. Citra merek

Berdasarkan hasil analisis regresi berganda dengan uji $\mathrm{t}$ menunjukan nilai sig. $0,007<0,05$ berarti bahwa citra merek berpengaruh signifikan terhadap keputusan pembelian. Sama seperti penelitian terdahulu yang dilakukan Johan Samuel Siregar, Erni Widiastuti (2017) hasil penelitiannya menjelaskan bahwa citra merek berpengaruh signifikan terhadap keputusan pembelian. Untuk itu dalam 
upaya meningkatkan volume penjualan produk diharapkan perusahan harus menguatkan citra merek produknya.Agar konsumen lebih percaya pada produk-produk perusahaan tersebut. Upaya yang dapat dilakukan perusahaan untuk menjaga citra merek ialah dengan selalu menjaga kualitas baik produknya, menjual produk dengan harga yang kompetitif dan memberi pelayanan penjualan yang sebaik-baiknya.

\section{Harga}

$\begin{array}{cc}\text { Berdasarkan } & \text { hasil } \\ \text { analisis regresi berganda }\end{array}$ dengan uji $\mathrm{t}$ menunjukan nilai sig. $0,067>0,05$ berarti bahwa harga tidak berpengaruh signifikan terhadap keputusan pembelian. Sama seperti penelitian terdahulu yang dilakukan Malonda Delsy, Joyce Laplan, Yunita Mandagle (2018) hasil penelitiannya menjelaskan bahwa harga tidak berpengaruh signifikan terhadap keputusan pembelian. Hasil ini menjelaskan bahwa sebagian konsumen tidak mempertimbangkan harga sebagai keputusan pembelian. Mungkin sebagian konsumen ada yang lebih mempertimbangkan harga. Tetapi untuk konsumen yang mementikan mutu, harga bukanlah masalah bagi mereka selama suatu produk dapat memuaskan keinginan dan kebutuhannya.

3. Kualitas produk

Berdasarkan hasil analisis regresi berganda dengan uji $\mathrm{t}$ menunjukan nilai sig. $0,226>0,05$ berarti bahwa kualitas produk tidak berpengaruh signifikan terhadap keputusan pembelian. Penelitian ini menolak penelitian terdahulu yang
dilakukanJohan Samuel Siregar, Erni Widiastuti (2017) hasil penelitiannya menjelaskan bahwa kualitas produk berpengaruh signifikan terhadap keputusan pembelian. Hasil ini menjelaskan bahwa sebagian konsumen tidak mempertimbangkan kualitas produk sebagai keputusan pembelian. Mungkin konsumen sudah terlalu percaya akan keunggulan produk Handphone Samsung (berbasis android). Tetapi untuk konsumen yang belum percaya akan kualitas produk handphone Samsung pasti akan mempertimbangkan apakah handphone Samsung (berbasis android) dapat memuaskan keinginan dan kebutuhannya.

\section{KESIMPULAN}

Setelah melakukan analisis data dan membahas tentang citra merek, harga, kualitas produk terhadap keputusan pembelian hansphone Samsung (berbasis android) maka penulis dapat menggambil kesimpulan:

1. Berdasarkan hasil analisis regresi berganda dengan uji $\mathrm{F}$ bahwa $F_{\text {hitung }}$ sebesar 26,640 > $F_{\text {tabel }}$ sebesar 2.70 dan nilai signifikasi $0,000<0,05$. Sehingga dapat disimpulkan bahwa citra merek, harga, kualitas produk secara simultan berpengaruh signifikan terhadap keputusan pembelian handphone Samsung (berbasis android). Sama seperti penelitian terdahulu yang dilakukan Johan Samuel Siregar, Erni Widiastuti (2017) hasil penelitiannya menjelaskan bahwa citra merek, harga, kualitas produk secara simultan berpengaruh signifikan terhadap keputusan pembelian produk batik di Danar Hadi Surakarta. Untuk itu dalam upaya meningkatkan volume penjualan produk diharapkan perusahan selalu menjaga 
kualitas baik produknya, menjual produk dengan harga yang kompetitif dan memberi pelayanan penjualan yang sebaik-baiknya.

2. Berdasarkan hasil analisis regresi berganda dengan uji t menunjukan nilai sig. $0,007<$ 0,05 bahwa citra merek secara parsial berpengaruh signifikan terhadap keputusan pembelian handphone Samsung (berbasis android). Sama seperti penelitian terdahulu yang dilakukan Johan Samuel Siregar, Erni Widiastuti (2017) hasil penelitiannya menjelaskan bahwa citra merek secara parsial berpengaruh signifikan terhadap keputusan pembelian produk batik di Danar Hadi Surakarta. Untuk itu dalam upaya meningkatkan volume penjualan produk diharapkan perusahan harus menguatkan citra merek produknya. Agar konsumen lebih percaya pada produk-produk perusahaan tersebut. Upaya yang dapat dilakukan perusahaan untuk menjaga citra merek ialah dengan selalu menjaga kualitas baik produknya, menjual produk dengan harga yang kompetitif dan memberi pelayanan penjualan yang sebaik-baiknya.

3. Berdasarkan hasil analisis regresi berganda dengan uji $t$ menunjukan nilai sig. 0,067 > 0,05 bahwa harga secara parsial tidak berpengaruh signifikan terhadap keputusan pembelian handphone Samsung (berbasis android). Sama seperti penelitian terdahulu yang dilakukan Malonda Delsy, Joyce Laplan, Yunita Mandagle (2018) hasil penelitiannya menjelaskan bahwa harga secara parsial tidak berpengaruh signifikan terhadap keputusan pembelian handphone Samsung pada seluruh gerai-gerai seluler di IT Manado. Hasil ini menjelaskan bahwa sebagian konsumen tidak mempertimbangkan harga sebagai keputusan pembelian. Mungkin sebagian konsumen ada yang lebih mempertimbangkan harga. Tetapi untuk konsumen yang mementikan mutu, harga bukanlah masalah bagi mereka selama suatu produk dapat memuaskan keinginan dan kebutuhannya.

4. Berdasarkan hasil analisis regresi berganda dengan uji $t$ menunjukan menunjukan nilai sig. 0,226>0,05 berarti bahwa kualitas produk secara parsial tidak berpengaruh signifikan terhadap keputusan pembelian handphone Samsung (berbasis android) . Penelitian ini menolak penelitian terdahulu yang dilakukan Johan Samuel Siregar, Erni Widiastuti (2017) hasil penelitiannya menjelaskan bahwa kualitas produk secara parsial berpengaruh signifikan terhadap keputusan pembelian produk batik di Danar Hadi Surakarta. Hasil ini menjelaskan bahwa sebagian konsumen tidak mempertimbangkan kualitas produk sebagai keputusan pembelian. Mungkin konsumen sudah terlalu percaya akan keunggulan produk Handphone Samsung (berbasis android). Tetapi untuk konsumen yang belum percaya akan kualitas produk handphone Samsung pasti akan mempertimbangkan apakah handphone Samsung (berbasis android) dapat memuaskan keinginan dan kebutuhannya. 


\section{DAFTAR PUSTAKA}

Fandi Tjiptono. 2011. Strategi Pemasaran. Yogyakarta: Penerbit Andi.

Ghozali, Imam. 2011. Aplikasi Analisis Multivariate dengan Program IBM SPSS19.Semarang: Badan Penerbit Universitas Diponegoro.

Harini . 2008. Makro Ekonomi Pengatar . Jakarta ; PT Gramedia Pustaka Utama.

Jajat Kristanto. 2011. Manjemen Pemasaran Internasional Sebuah Pendekatan Strategi.Jakarta:Erlangga.

Johan Samuel Siregar, Erni Widiastuti Analisis pengaruh Brand image, kualitas produk dan harga terhadap keputusan pembelian produk batik di Danar Hadi Surakarta Fakultas Ekonomi Universitas Surakarta ISSN 20852215/Vol.15/No.4/Oktober 2017.

Kotler, Philip and Keller, Kevin Lane. 2012. Marketing Management. 14th edition.New Jersey: Prentice.

Kotler, Philip and Amstrong, Gary. 2012. Priciples of Marketing Global 14thedition.New Jersey: Prentice.

Kotler, Philips and Garry Amstrong. 2015. Prinsip-Prinsip Pemasaran.Jilid 1. Edisi 12. Diterjemahkan oleh Ari Setyaningrum. Jakarta: Erlangga.

Kotler ,Philips dan Kelvin Lane Keller. 2016. Marketing Management 15th Edition. New Jersey: Pearson Education, Inc.

Machfodz, Mahmud.2005.Pengatar Pemasaran Modern. Yogyakarta .Upp Amp Ykpn.

Malonda Delsy, Joyce Laplan, Yunita Mandagle, Analisis Citra merek, harga, kualitas terhadap keputusan pembelian handphone samsung pada seluruh gerai-gerai seluler di IT Manado fakultas Ekonomi dan bisnis jurusan manajemen Universitas Sam Ratulangi manado ISSN 23031174/Vol.6/No.4/September 2018.

Mentari kasih labiro, pengaruh citra merek,harga dan kualitas produk terhadap keputusan pembelian produk purbasari lipstick matte .Yogyakarta :Universitas Sanata Dharma Yogyakarta . 2017: 1-5. 15 Maret 2019.

Nela Evelina. "Pengaruh Citra Merek, Kualitas Produk, Harga dan Promosi terhadap Keputusan Pembelian Kartu Perdana Telkom Flexi (Studi Kasus Pada Konsumen Telkom Flexi di Kecamatan Kota Kudus Kabupaten Kudus" Diponegoro Journal of Social and Politic. Semarang :Universitas Diponegoro. 2012: 1-11. 3 Februari 2019.

Ratri, Lutiary Eka. 2007. Strategi Memenangkan Persaingan Pasar. Jakarta: Salemba Empat.

Sarini Kodu. 2013. "Harga, Kualitas Produk dan Kualitas Pelayanan Pengaruhnya Terhadap Keputusan Pembelian Mobil Toyota Avanza". Jurnal EMBA. Vol. 1, No. 03. 3 Februari 2019. Hal. 1251-1259.

Sugiyono. 2013. Metode Penelitian Kuantitatif, Kualitatif dan $R \& D$. Bandung:Alfabeta.

Tatik Suryani. 2013. PerilakuKonsumen di Era Internet.Yogyakarta: Grahallmu.

Vernando, "pengaruh citra merek, kualitas produk dan promosi terhadap keputusan pembelian smartphone Samsung".Yogyakarta :Universitas Sanata Dharma Yogyakarta . 2018: 48-63. 15 Maret 2019. 
Wangean, Ryanto Hariandy. 2014. Analisis Citra Merek, Kualitas Produk dan Harga Pengaruhnya terhadap Keputusan Pembelian Konsumen
Pada Mobil All New Kia Rio di Kota Manado. Vol.2 No.3 Februari 2019, Hal. 1715-1725. 